07

\title{
Влияние структуры гетерогенного нанокристаллического тела (песчаника) на динамику накопления микротрещин при трении
}

\author{
(С) В.И. Веттегрень ${ }^{1}$, А.В. Пономарев ${ }^{2}$, И.П. Щербаков ${ }^{1}$, Р.И. Мамалимов ${ }^{1}$ \\ ${ }^{1}$ Физико-технический институт им. А.Ф. Иофрфе РАН, \\ Санкт-Петербург, Россия \\ ${ }^{2}$ Институт фризики Земли им. О.Ю. Шмидта РАН, \\ Москва, Россия \\ E-mail: Victor.Vettegren@mail.ioffe.ru
}

(Поступила в Редакцию 25 января 2017 г.)

\begin{abstract}
При трении гетерогенного материала - песчаника - наблюдаются вспышки триболюминесценции. Она возникает при релаксации возбуждения свободных радикалов $\equiv \mathrm{Si}-\mathrm{O}^{-}$. Эти радикалы образуются при разрывах связей $\mathrm{Si}-\mathrm{O}-\mathrm{Si}$ и располагаются на берегах микротрещин. Микротрещины образуются на границах микрокристаллов полевого шпата и кварца. Их размеры варьируются от $\sim 0.4$ до $\sim 7 \mu \mathrm{m}$. Образование микротрещин при трении приводит к откалыванию микрокристаллов полевого шпата и кварца от образца.
\end{abstract}

Работа выполнена при финансовой поддержке РФФИ (грант № 16-05-00137).

DOI: $10.21883 /$ FTT.2017.08.44758.18

\section{1. Введение}

Согласно современным представлениям, в основе механизма землетрясений лежит неустойчивость скольжения земных плит. Она может быть порождена резкими изменениями коэффициента трения на контактах пород $[1,2]$. В результате изнашивания поверхности контактирующих пород сглаживаются и образуются так называемые ,зеркала скольжения“ коэффициент трения которых на порядок меньше, чем для подстилающей породы $[3,4]$. Экспериментальные исследования строения природных зеркал скольжения на поверхностях горных пород были проведены при помощи инфракрасной, рамановской и фотолюминесцентной спектроскопии в работах [5-7]. Обнаружено, что химическое строение природных зеркал скольжения отлично от строения подстилающей породы: они содержали нанокристаллы минералов, коэффициент трения которых был по крайней мере в несколько раз меньше, чем у кристаллов в подложке. В упомянутых работах было сделано предположение, что изменение строения зеркал скольжения обусловлено разрушением кристаллов под действием нормальных и касательных напряжений при трении.

Чтобы проверить это предположение, в [8] методами оптической микроскопии, фотолюминесцентной и рамановской спектроскопии исследовано строение поверхностного слоя толщиной $\sim 30 \mathrm{~nm}$, образовавшегося при трении друг о друга пластин рифейского (т.е. образовавшегося от 1650 до 650 млн. лет тому назад) песчаника, добытого на Кольском полуострове. До трения этот слой содержал кристаллы кварца, полевого шпата, монтмориллонита и анатаза с линейными размерами от нескольких десятков до сотен микрометров. Трение вызвало резкое уменьшение концентрации и размеров кристаллов кварца и полевого шпата. Чтобы исследовать механизм разрушения этих кристаллов, был использован метод триболюминесценции (TL). Она вызывается излучением свободных радикалов $\equiv \mathrm{Si}-\mathrm{O}^{-}$, которые образуются при разрывах связей $\mathrm{Si}-\mathrm{O}-\mathrm{Si}$ в кристаллах кварца и полевого шпата.

Временна́я зависимость TL представляет собой набор вспышек. Вероятно, такой вид TL обусловлен тем, что каждая вспышка отражает рождение микротрещин [9-11].

Цель настоящей работы - оценить размеры микротрещин и исследовать динамику их накопления при трении.

\section{2. Объект и методы исследования}

Для решения задачи была использована установка, описанная в [8]. Она состоит из вращающегося диска и прижатого к нему стержня из рифейского песчаника. Диаметр диска $140 \mathrm{~mm}$, диаметр стержня $9.5 \mathrm{~mm}$. Песчаник добывался из шурфов полуострова Средний на северном побережье Кольского полуострова. Линейная скорость вращения диска $v_{d}=26 \mathrm{~m} / \mathrm{s}$. Давление стержня на диск $\sim 1 \mathrm{MPa}$.

Излучение, возникающее при трении, через кварцевый световод подавалось на поверхность фотоэлектронного умножителя РЕМ 136, а с него - на вход аналоговоцифрового преобразователя ADS-3112. Там сигналы TL оцифровывались и с временны́м разрешением $2 \mathrm{~ns}$ записывались в память компьютера для дальнейшей обработки и хранения.

\section{3. Структура песчаника}

На рис. 1 показан фрагмент фотографии поверхности исследованного образца. Ранее проведенный анализ фо- 


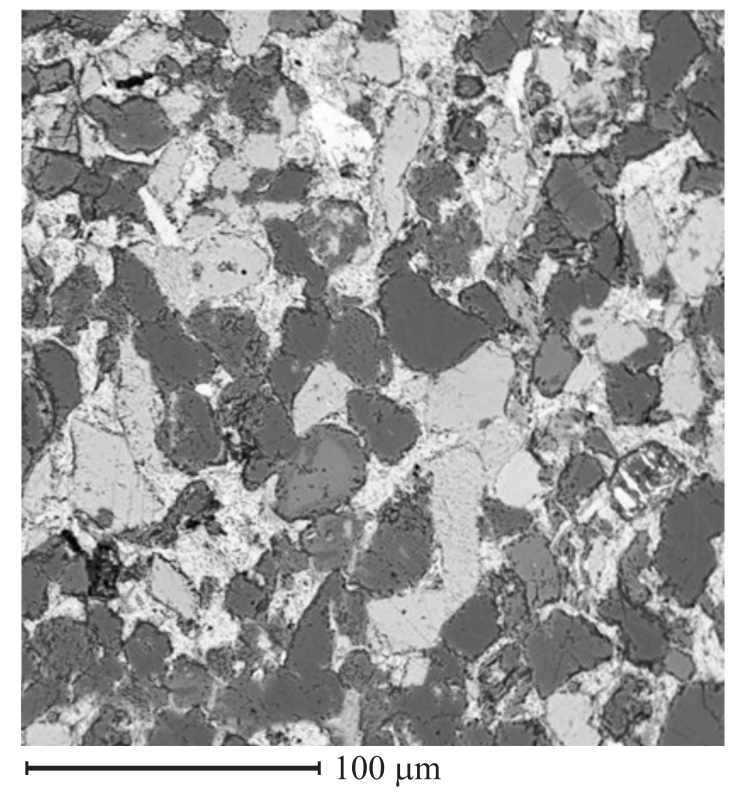

Рис. 1. Фотография поверхности песчаника.

тографий этого песчаника [6,7] показал, что около $80 \%$ его поверхности занимают кристаллы кварца и полевых шпатов (плагиоклаза и микроклина), 15\% - гидрослюды, $\sim 5 \%$ - анатаз и другие минералы. Размеры кристаллов кварца и полевых шпатов варьируются от $\sim 5$ до $\sim 100 \mu \mathrm{m}$ и в среднем составляют $\sim 60 \mu \mathrm{m}$. Кристаллы сложены из блоков с линейными размерами от $\sim 6$ до $\sim 20 \mathrm{~nm}[5-7]$.

\section{4. Динамика TL}

Фрагменты временно́й зависимости интенсивности TL показаны на рис. 2. Она представляет собой набор вспышек, интенсивность которых изменяется по крайней мере на порядок. Время между вспышками варьируется от $\sim 1$ до $\sim 50 \mu \mathrm{s}$, а наиболее вероятный интервал между их появлением $\sim 2.5 \mu$ s (рис. 3 ).

Каждая вспышка содержит от 5 до 20 наложенных друг на друга максимумов (рис. 4). Эти максимумы появляются с интервалом от $\sim 2$ до $\sim 7$ ns. Появление каждого максимума, по-видимому, соответствует рождению микротрещины, на берегах которой располагаются возбужденные свободные радикалы [9-11].

Оценим их размер. С этой целью дифференцировалась временна́я зависимость TL и была найдена максимальная величина производной $d N / d t$, где $N-$ число вспышек, $t$ - время. Оказалось, что она равна $\sim 56 \mathrm{~ns}^{-1}$. Трещина имеет две поверхности, поэтому имеем

$$
4(d L / d t)=Q d N / d t \approx Q \cdot 56
$$

где $d L / d t$ - скорость роста микротрещины, а $Q-$ коэффициент пропорциональности.
Чтобы оценить $d L / d t$, воспользуемся результатами работ [9-12]. Авторы исследовали механизм образования микротрещин на поверхностях кварца и гранитов под влиянием удара бойком по их поверхности. Было
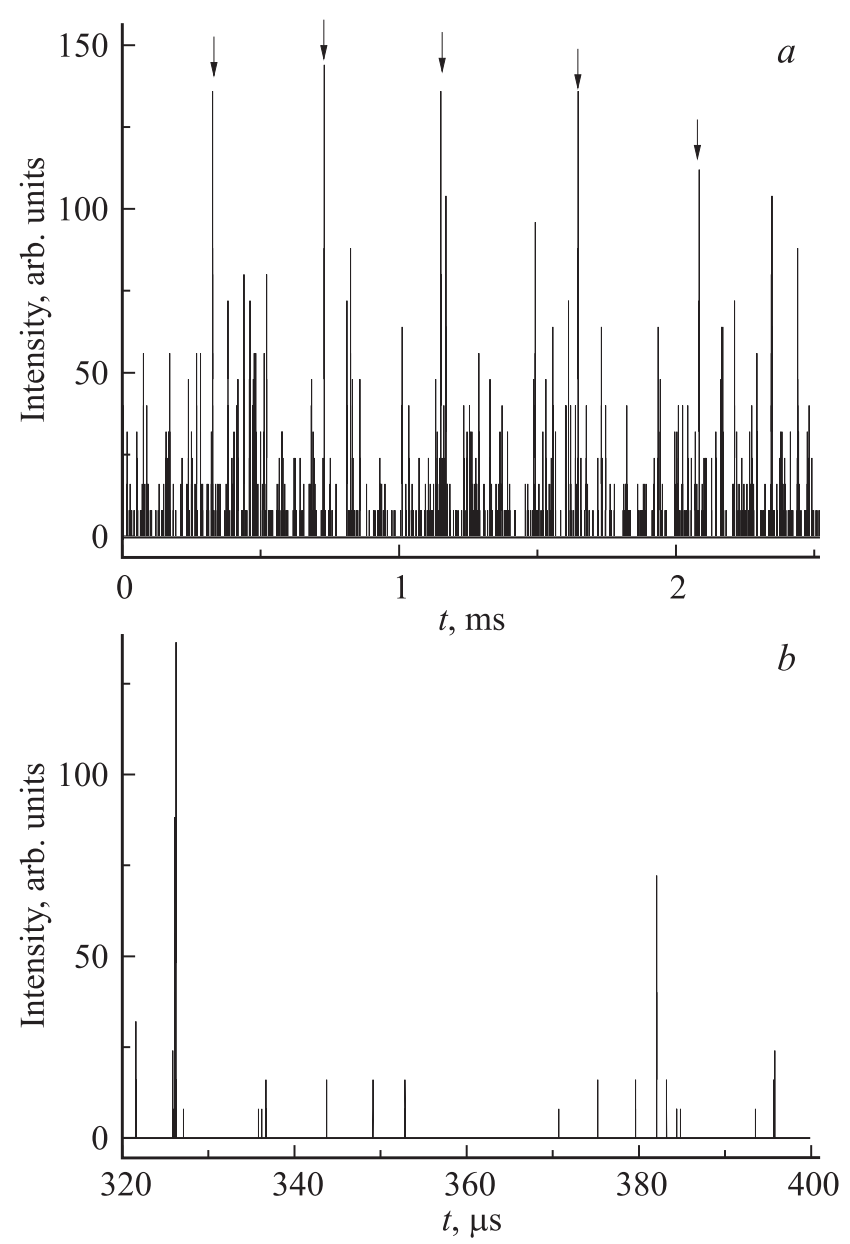

Рис. 2. Фрагменты временны́х зависимостей интенсивности вспышек в различных временны́х интервалах. $a-$ от 0 до $2.5 \mathrm{~ms}, b-$ от 320 до $400 \mu \mathrm{s}$. Стрелками на части $a$ отмечены вспышки, вызванные колебаниями конца стержня.

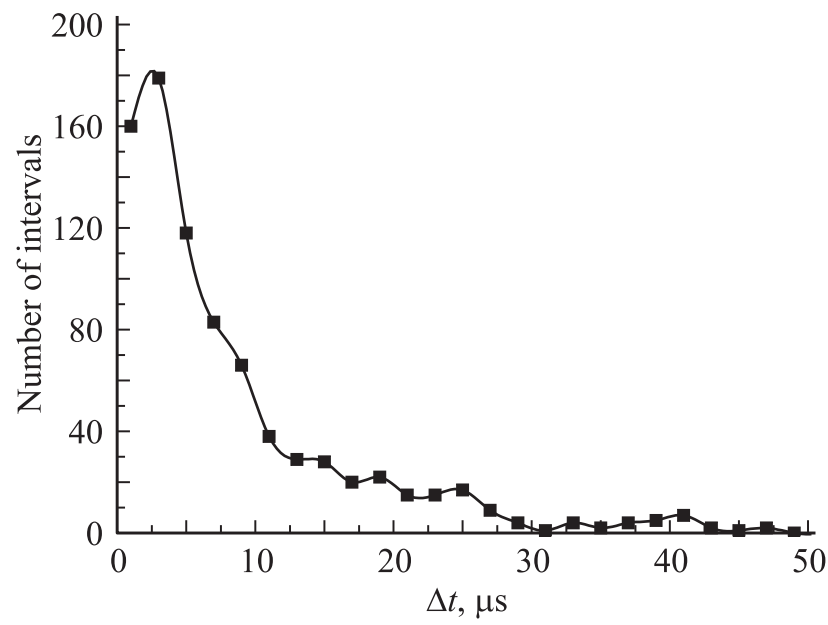

Рис. 3. Распределение интервалов между вспышками TL. 


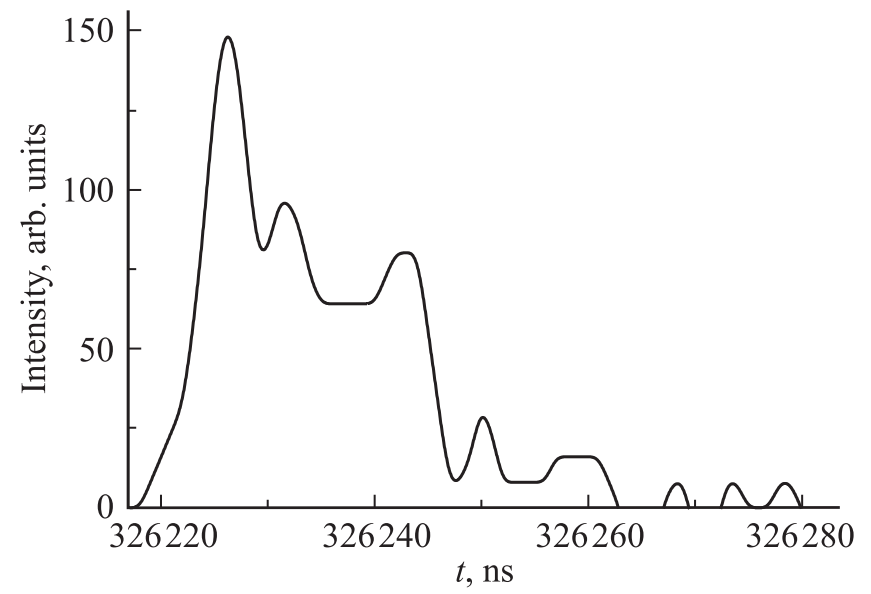

Рис. 4. Типичная вспышка TL.

установлено, что ударная волна вызывает появление микротрещин на поверхности этих тел. Чтобы оценить скорость такой волны, из песчаника были изготовлены стержни диаметром $\sim 1 \mathrm{~cm}$ и длиной $5 \mathrm{~cm}$. Затем по одному из концов ударяли бойком и с помощью пластинки из пьезокерамики CTS-19 измеряли время появления упругой волны на другом конце (методика измерений описана в $[10,11])$. Оказалось, что она равна $\sim 700 \mathrm{~m} / \mathrm{s}$. С другой стороны, известно, что максимальная скорость роста трещин приблизительно равна $1 / 3$ от скорости роста поперечной звуковой волны [13]. В песчаниках она равна $\sim 2 \mathrm{~km} / \mathrm{s}$ [14]. Отсюда получаем, что скорость роста микротрещин $\sim 700 \mathrm{~m} / \mathrm{s}$.

Подставив это значение в (1), находим $Q \approx 50 \mathrm{~nm}$. Используя это значение $Q$ и временну́ю зависимость интенсивности вспышек, мы оценили длину микротрещин. Оценки показали, что максимальная длина трещин $L \approx 7 \mu \mathrm{m}$, а минимальная $-\sim 0.4 \mu \mathrm{m}$. Эти значения по крайней мере в несколько раз меньше размеров кристаллов кварца и полевых шпатов.

\section{5. Влияние структуры на динамику трещин}

Выше уже отмечалось, что наиболее вероятный интервал между рождением микротрещин составляет $\sim 2.5 \mu \mathrm{s}$. За это время поверхность вращающегося диска успевает пройти путь $\sim 2.5 \mu \mathrm{s} \cdot 26 \mu \mathrm{m} / \mu \mathrm{s} \approx 65 \mu \mathrm{m}$. Это значение близко к среднему размеру кристаллов кварца и полевых шпатов $(\sim 60 \mu \mathrm{m})$. Вероятно, при трении разрушаются границы между микрокристаллами, что приводит к их отрыву от диска и стержня. Действительно, линейные размеры частиц порошка, образовавшегося при трении, имели два значения: $\sim 1-3 \mu \mathrm{m}$ и $\sim 40-70 \mu \mathrm{m}$ (рис. 5). Порошок с линейными размерами зерен $\sim 1-3 \mu \mathrm{m}$, по-видимому, образуется при разрушении границ между кристаллами, а с размерами от $\sim 40-70 \mu \mathrm{m}-$ при отделении зерен кварца и полевых шпатов от образца песчаника.

Как уже указывалось, каждая вспышка содержит от $\sim 5$ до $\sim 20$ наложенных друг на друга максимумов, которые появляются через $\sim 2-7 \mathrm{~ns}$. Вероятно, для разрушения границы между кристаллами необходимо создать от 5 до 20 микротрещин. Тогда время между вспышками затрачивается на перераспределение напряжений после образования одной микротрещины, что вызывает появление следующей микротрещины и т.д., до отделения микрокристалла от образца.

Вернемся к рассмотрению рис. 2. Из него видно, что при трении наблюдается ряд весьма интенсивных вспышек (отмечены стрелками), которые появляются через определенный интервал времени $\sim 0.44 \mathrm{~ms}$. За это время поверхность вращающегося диска перемещается на $\sim 9.3 \mathrm{~mm}$, что близко к диаметру стержня $(\sim 9.5 \mathrm{~mm}$,
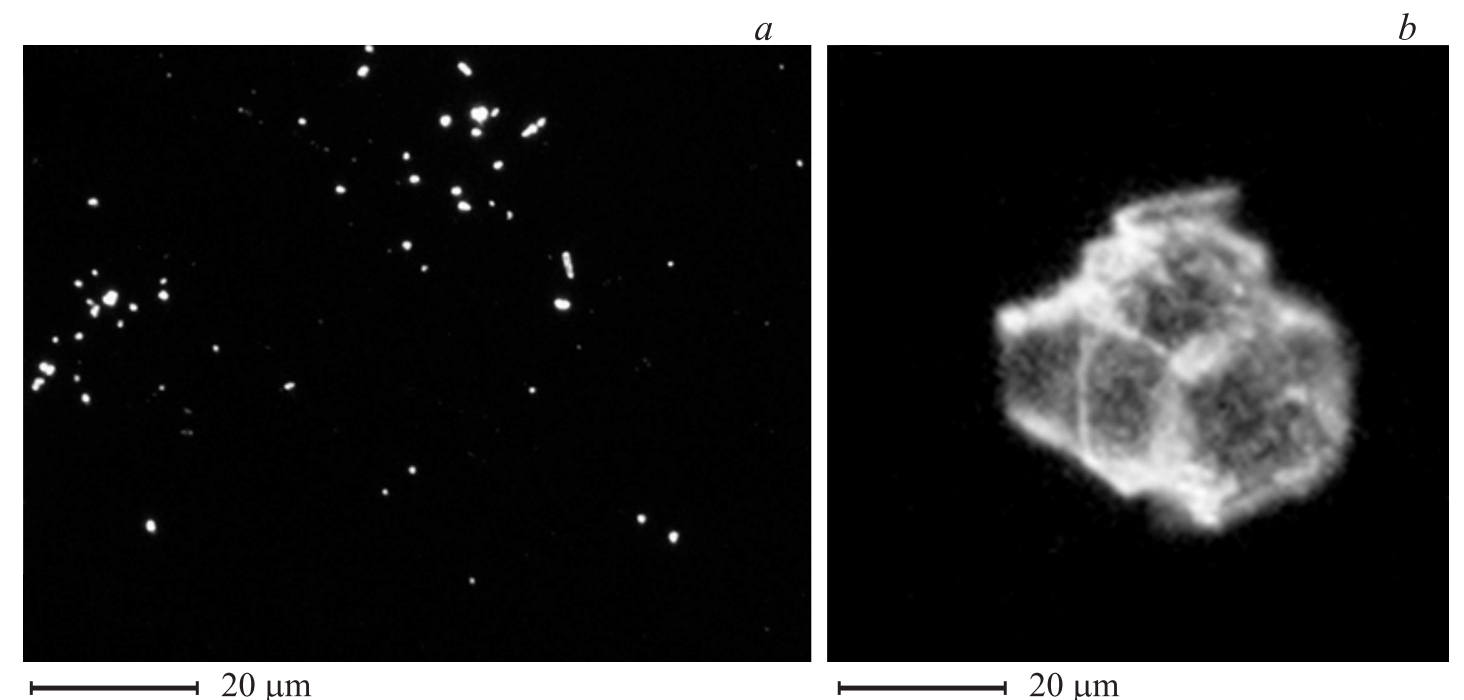

Рис. 5. Фотографии частиц порошка. $a-$ с размерами $\sim 1-3 \mu \mathrm{m}, b-$ с размером $\sim 30 \mu \mathrm{m}$. 
см. выше). Вероятно, эти вспышки вызваны колебаниями конца стержня при трении.

\section{6. Заключение}

При трении рифейского песчаника связи $\mathrm{Si}-\mathrm{O}-\mathrm{Si}$ в кристаллических решетках кварца и полевого шпата разрываются. После их разрыва образуются микротрещины, на берегах которых располагаются ,разорванные межатомные связи“ - возбужденные свободные радикалы $\equiv \mathrm{SiO}^{-}$. При релаксации возбуждения возникает люминесценция, которая имеет вид отдельных вспышек. Их интенсивность пропорциональна размеру микротрещин. Это позволило оценить размеры микротрещин: от $\sim 0.4$ до $\sim 7 \mu \mathrm{m}$. Микротрещины рождаются группами через $\sim 6-7 \mathrm{~ns}$ на границах микрокристаллов кварца и полевого шпата. Каждая из групп содержит от 7 до 20 микротрещин. Образование такой группы приводит к откалыванию от образца микрокристалла кварца или полевого шпата.

\section{Список литературы}

[1] J.H. Dietrich. J. Geophys. Res. 77, 3690 (1972).

[2] C.H. Scholz. The mechanics of earthquakes and faulting. $2^{\text {nd }}$ ed. Cambridge University Press, Cambridge (2002). $471 \mathrm{p}$.

[3] G. Di Toro, R. Han, T. Hirose, N. De Paola, S. Nielsen, K. Mizoguchi, F. Ferri, M. Cocco, T. Shimamoto. Nature 471, 494 (2011).

[4] A. Niemeijer, G. Di Toro, W.A. Griffith, A. Bistacchi, S. A.F. Smith, S. Nielsen. J. Struct. Geology 39, 2 (2012).

[5] Г.А. Соболев, С.М. Киреенкова, Ю.А.Морозов, А.И. Смульская, В.И. Веттегрень, В.Б. Кулик, Р.И. Мамалимов. Физика Земли 9-10, 17 (2012).

[6] Г.А. Соболев, В.И. Веттегрень, С.М. Киреенкова, В.Б. Кулик, Р.И. Мамалимов, Ю.А. Морозов, А.И. Смульская, И.П. Щербаков. Нанокристаллы в горных породах. ГЕОС, М. (2016). $102 \mathrm{c}$.

[7] Г.А. Соболев, В.И. Веттегрень, С.М. Киреенкова, В.Б. Кулик, Ю.А. Морозов, А.И. Смульская. Физика Земли 6, 7 (2007).

[8] В.И. Веттегрень, А.В. Пономарев, Г.А. Соболев, И.П. Щербаков, Р.И. Мамалимов. В.Б. Кулик, А.В. Патонин. ФТТ 59, 3, 569 (2017).

[9] В.И. Веттегрень, В.С. Куксенко, И.П. Щербаков. ЖТФ 81, 4, 148 (2011).

[10] В.И. Веттегрень, В.С. Куксенко, И.П. Щербаков. ФТТ 54, 7, 1342 (2012).

[11] В.И. Веттегрень, В.С. Куксенко, Р.И. Мамалимов, И.П. Щербаков. Физика Земли 5, 58 (2012).

[12] В.И. Веттегрень, И.П. Щербаков, Р.И. Мамалимов. ФТТ 58, 11, 2252 (2016)

[13] В.Р. Регель, А.И. Слуцкер, Э.Е. Томашевский. Кинетическая природа прочности твердых тел. Наука, М. (1974). $560 \mathrm{c}$.

[14] J.H. Schön. Physical properties of rocks. Elsevier, Amsterdam (2011). 480 p. 